\title{
Incorporação ao solo de substrato contendo micélio e conídios de Pochonia chlamydosporia para o manejo de Meloidogyne javanica
}

\author{
Soil amendment with substrate containing mycelium and conidia of Pochonia \\ chlamydosporia for the management of Meloidogyne javanica
}

\author{
Rosangela Dallemole-Giaretta ${ }^{\mathrm{I}}$ Leandro Grassi de Freitas ${ }^{\mathrm{II}}$ Deborah Magalhães Xavier ${ }^{\mathrm{II}}$ \\ Ronaldo João Falcão ZoocaII Silamar Ferraz ${ }^{\text {II }}$ Everaldo Antônio Lopes ${ }^{\text {III }}$
}

RESUMO

Os clamidósporos são os principais propágulos utilizados como fonte de inóculo de Pochonia chlamydosporia em experimentos envolvendo o biocontrole do nematoide das galhas. O presente trabalho teve por objetivo avaliar o controle de Meloidogyne javanica em tomateiro por meio da aplicação ao solo de grãos de arroz colonizados pelo fungo contendo apenas micélio e conídio, sem a presença de clamidósporos. $O$ isolado de P. chlamydosporia $\mathrm{PC}-10$ foi cultivado por 15 dias a $26^{\circ} \mathrm{C}$ em arroz previamente esterilizado em forno microondas. Dois experimentos foram conduzidos simultaneamente em casa de vegetação. No experimento 1 , vasos de $2 L$ de capacidade foram preenchidos com mistura solo:areia $(1: 1, v: v)$, contendo $3 \mathrm{~g} \mathrm{~kg}^{-1}$ de solo de grãos de arroz colonizados pelo antagonista. No experimento 2 , o fungo foi adicionado ao solo de vasos de 0,5L nas doses de 1, 5, 10, 15, 20, 25 ou $30 \mathrm{~g} \mathrm{~kg}^{-1}$ de solo. Em seguida, o substrato de cada vaso foi infestado com 4.000 ovos de M. javanica e, após 15 dias, uma plântula de tomate foi transplantada. No experimento 1 , a aplicação do fungo ao solo reduziu o número de galhas e de ovos do nematoide em $40 \%$ e $72,83 \%$, respectivamente. No experimento 2, houve redução do número de ovos a partir de doses de $5 \mathrm{~g} \mathrm{~kg}^{-1} \mathrm{de}$ solo e no número de galhas, principalmente, nas doses de 25 e $30 \mathrm{~g}$ $\mathrm{kg}^{-1}$ de solo. Conclui-se que P. chlamydosporia Pc-10 controlou M. javanica em tomateiro, mesmo quando aplicado ao solo na forma de grãos de arroz colonizados e sem a presença de clamidósporos.

Palavras-chave: controle biológico, fungo nematófago, nematoide das galhas.

\section{ABSTRACT}

Chlamydospores are the main propagules used as source of inoculum of Pochonia chlamydosporia in biocontrol experiments of root-knot nematodes. The objective of this study was to evaluate the control of Meloidogyne javanica on tomato plants by the soil application of rice grains colonized by Pochonia chlamydosporia containing just mycelium and conidia, without chlamydospores. The fungus (isolate Pc-10) was grown for 15 days at $26^{\circ} \mathrm{C}$ on grains of rice, previously sterilized in microwave oven. Two experiments were simultaneously carried out under greenhouse conditions. In the experiment 1, 2-L pots were filled with a soil:sand mixture $(1: 1, \mathrm{v}: \mathrm{v})$ containing $3 \mathrm{~g} \mathrm{~kg}^{-1}$ of soil of rice grains colonized by the antagonist. In the experiment 2 , the fungus was added into the soil of $0.5 \mathrm{~L}$ pots at the doses of 5, 10, 15, 20, 25 or $30 \mathrm{~g} \mathrm{~kg}^{-1}$ of soil. The soil of each pot was infested with 4,000 eggs of M. javanica and one tomato seedling was transplanted in each pot after fifteen days. In the experiment 1, the application of the fungus into the soil reduced the number of galls and eggs of the nematode by $40 \%$ and $72.83 \%$, respectively. In the experiment 2 , it was observed the reduction of the number of eggs from the dose of $5 \mathrm{~g} \mathrm{~kg}^{-1}$ of soil and of the number of galls, particularly at the doses of 25 and $30 \mathrm{~g} \mathrm{~kg}^{-1}$ of soil. As a conclusion, P. chlamydosporia controlled M. javanica on tomato plants even when applied into the soil as colonized-rice grains and without chlamydospores.

Key words: biological control, nematophagous fungus, root-knot nematode.

\section{INTRODUÇÃO}

O fungo nematófago Pochonia chlamydosporia Zare \& Gams (sin. Verticillium chlamydosporium Goddard) é um parasita facultativo de ovos de nematoides e tem sido comumente estudado como agente de controle biológico do nematoide das galhas e de cistos (HIDALGO-DIAZ et al., 2000; KERRY \& BOURNE, 2002; LOPES et al., 2007; DALLEMOLE-GIARETTA et al., 2012). Além disso, o antagonista pode reduzir a população

IUniversidade Tecnológica Federal do Paraná (UTFPR), Campus de Pato Branco, Pato Branco, PR, Brasil.

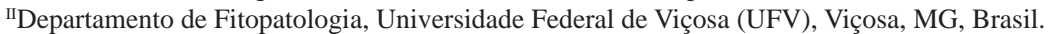

IIInstituto de Ciências Agrárias, UFV, Campus Rio Paranaíba, 36570-000, Rio Paranaíba, MG, Brasil. E-mail: everaldolopes@ufv.br. Autor para correspondência. 
de outras espécies de fitonematoides, como, por exemplo, Rotylenchulus reniformis Linford \& Oliveira, Nacobbus aberrans (Thorne) Thorne \& Allen, Pratylenchus sp. Filipjev, Radopholus similis (Cobb) Thorne e Helicotylenchus sp. Steiner (WANG et al., 2005; PÉREZ-RODRÍGUEZ et al., 2007; FREITAS et al., 2009).

Aliada à capacidade de redução da produção de ovos dos patógenos nas raízes das plantas, a habilidade de $\boldsymbol{P}$. chlamydosporia em produzir clamidósporos durante o cultivo massal em substrato sólido é um dos critérios usualmente utilizados para a seleção de isolados em programas de controle biológico de nematoides (KERRY \& BOURNE, 2002). Os clamidósporos são estruturas responsáveis pela sobrevivência do fungo no solo e, por isso, são preferencialmente utilizados como fonte de inóculo, em detrimento ao micélio e conídios (KERRY \& BOURNE, 2002; MAUCHLINE et al., 2002).

No entanto, é possível que o fungo possa controlar nematoides e ainda sobreviver no solo sem que clamidósporos tenham sido adicionados como fonte de inóculo. Com base em tal hipótese, o objetivo do trabalho foi avaliar o controle de Meloidogyne javanica (Treub) Chitwood em tomateiros cultivados em casa de vegetação por $\boldsymbol{P}$. chlamydosporia Pc10 , aplicado ao solo por meio de grãos de arroz colonizados, contendo apenas somente conídios e fragmentos de micélio do fungo.

\section{MATERIAL E MÉTODOS}

Cultivo de $\boldsymbol{P}$. chlamydosporia var. chlamydosporia Pc-10

Em sacos de polipropileno autoclaváveis (38cm de largura x $45 \mathrm{~cm}$ de comprimento), foram colocados $100 \mathrm{~g}$ de grãos de arroz e $70 \mathrm{~mL}$ de água destilada. Após uma hora de repouso, o substrato presente em cada embalagem foi manualmente distribuído até a obtenção de uma camada de aproximadamente $2 \mathrm{~cm}$ de altura. Em seguida, cada embalagem foi colocada individualmente no interior de forno de micro-ondas (Panasonic ${ }^{\circledR}$, Modelo NN72098H, 900 W) e o substrato foi esterilizado utilizando a potência máxima do equipamento durante três minutos. No final da esterilização, cada embalagem foi lacrada com o auxílio de uma borracha.

Em condições assépticas, cinco discos de micélio de $\boldsymbol{P}$. chlamydosporia var. chlamydosporia Pc-10 (5mm de diâmetro) foram adicionados em cada embalagem. O inóculo do fungo foi obtido após cultivo por quinze dias em 'Corn Meal Agar' (CMA) a $25^{\circ} \mathrm{C}$. Em seguida, os sacos foram armazenados por 15 dias no escuro a $25^{\circ} \mathrm{C}$. Ao final deste período, coletaram-se amostras do arroz colonizado pelo fungo para análise ao microscópio (KERRY \& BOURNE, 2002). O fungo não produziu clamidósporos no substrato, apenas micélio e conídios.

\section{Montagem dos experimentos}

Dois experimentos foram realizados simultaneamente em casa de vegetação do Departamento de Fitopatologia, da Universidade Federal de Viçosa, Viçosa - MG, Brasil. A temperatura média durante os experimentos foi de $22,3^{\circ} \mathrm{C}$, a média das máximas foi $29,3^{\circ} \mathrm{C}$ e a média das mínimas foi $15,3^{\circ} \mathrm{C}$.

O substrato utilizado para o cultivo dos tomateiros cv. "Santa Clara" foi composto por uma mistura solo e areia, na proporção 1:1 (v:v), previamente tratada com brometo de metila. O inóculo de $\boldsymbol{M}$. javanica foi constituído de ovos obtidos de populações puras, coletadas de raízes de tomateiros mantidos em casa de vegetação. Os ovos foram extraídos pela técnica de HUSSEY \& BARKER (1973), modificada por BONETI \& FERRAZ (1981).

No experimento 1, vasos plásticos de 2L de capacidade foram preenchidos com $2 \mathrm{~kg}$ da mistura solo:areia e $6 \mathrm{~g}$ de substrato colonizado por P. chlamydosporia, correspondendo a $3 g$ de inóculo fúngico por kg de solo. Em seguida, o solo de cada vaso foi infestado com $2 \mathrm{~mL}$ contendo 4.000 ovos de M. javanica. O inóculo do nematoide foi adicionado em quatro orifícios de aproximadamente $5 \mathrm{~cm}$ de profundidade, equidistantes $5 \mathrm{~cm}$ na parte central do vaso. O solo foi mantido úmido em $60 \%$ da capacidade de campo por quinze dias, quando uma plântula de tomateiro Santa Clara foi transplantada em cada vaso. Plantas cultivadas em solo sem $\boldsymbol{P}$. chlamydosporia e infestado ou não com $\boldsymbol{M}$. javanica foram mantidas como testemunhas.

No experimento 2, os mesmos procedimentos metodológicos do experimento 1 foram adotados, exceto pelo cultivo das plantas em vasos plásticos de $0,5 \mathrm{~L}$, contendo $0,5 \mathrm{~kg}$ de solo e a aplicação de diferentes quantidades de substrato colonizado pelo fungo $(1,5,10,15,20,25$ ou $30 \mathrm{~g}$ $\mathrm{kg}^{-1}$ de solo).

O delineamento estatístico de ambos os experimentos foi do tipo inteiramente casualizado, com oito repetições por tratamento e a parcela experimental representada por uma planta mantida em vaso. A altura das plantas, a massa da parte aérea e das raízes e os números de galhas e de ovos por sistema radicular foram avaliados 45 dias após o 
transplantio das plântulas. Os ovos foram extraídos das raízes similarmente ao realizado durante o preparo do inóculo do nematoide. Os números de galhas e de ovos foram determinados após contagem direta a olho nu ou com auxílio de câmara de Peters e observação em microscópio estereoscópico, respectivamente. Além disso, a população do fungo no solo foi avaliada no experimento 2. Para isso, uma amostra de $10 \mathrm{~g}$ de solo foi coletada em cada repetição e formou-se uma amostra composta por tratamento. Diluições em série (até $10^{-3}$ ) foram realizadas a partir de $1 \mathrm{~g}$ do solo da amostra composta (KERRY \& BOURNE, 2002). As suspensões de solo foram distribuídas na superfície de meio semi-seletivo (GASPARD et al.,1990), com três repetições por tratamento. As placas foram armazenadas em câmara de crescimento a $25^{\circ} \mathrm{C}$ no escuro. O número de unidades formadoras de colônia (UFC) foi avaliado ao final de 15 dias.

Os dados obtidos foram submetidos à análise estatística (teste F, 5\% de probabilidade). No experimento 2, as médias dos tratamentos foram comparadas com a testemunha infestada por meio do teste de Dunnett (5\% de probabilidade) e análise de regressão (5\% de probabilidade) foi realizada para avaliação do efeito das doses do substrato colonizado por $\boldsymbol{P}$. chlamydosporia sobre M. javanica.

\section{RESULTADOS E DISCUSSÃO}

A incorporação ao solo de $3 g \mathrm{~kg}^{-1}$ de solo de substrato colonizado por $\boldsymbol{P}$. chlamydosporia não aumentou a altura e a fitomassa dos tomateiros no experimento 1 , mesmo quando comparado com a testemunha infestada com M. javanica (Tabela 1). Similarmente, nenhuma dose do substrato colonizado pelo fungo teve efeito na altura e na massa de raízes da planta no experimento 2 (Tabela 2). Todavia, a massa da parte aérea foi incrementada de $16,74 \%$ a 33,13\% em plantas cultivadas em vasos que receberam doses do fungo a partir de $5 \mathrm{~g} \mathrm{~kg}^{-1}$ de solo (Tabela 2).

A promoção de crescimento de plantas promovida por $\boldsymbol{P}$. chlamydosporia já foi constatada em plantas de tomate, trigo e cevada (HIDALGODÍAZ et al., 2000; MONFORT et al., 2005; MACIÁVICENTE et al., 2009). No presente trabalho, a habilidade do fungo em aumentar a massa da parte aérea foi dependente da dose aplicada ao solo. Adicionalmente, a maior quantidade de matéria orgânica proveniente dos grãos de arroz colonizados pelo fungo em parcelas com mais de $5 \mathrm{~g}$ do substrato/ kg de solo, em comparação com o experimento 1 (3g $\mathrm{kg}^{-1}$ de solo), também podem ter influenciado no crescimento das plantas. Todavia, em pesquisa envolvendo o mesmo patossistema do presente trabalho, a adição de 2,5g de arroz não colonizado por Paecilomyces lilacinus por $250 \mathrm{~g}$ de solo não aumentou no crescimento de tomateiros infectados por M. javanica (FREITAS et al., 1999). Assim, é possível que a interação de $\boldsymbol{P}$. chlamydosporia com a planta, mais do que a matéria orgânica do substrato, tenha sido responsável por estimular o crescimento das plantas (MONFORT et al., 2005). No entanto, novos estudos envolvendo a incorporação de diferentes doses de grãos de arroz colonizados ou não pelo fungo seriam necessários para elucidar se o efeito tônico nas plantas deve-se à ação do fungo Pc10 ou da matéria orgânica.

O fungo $\boldsymbol{P}$. chlamydosporia reduziu o número de galhas e de ovos de $\boldsymbol{M}$. javanica em ambos os experimentos (Tabelas 1 e 2, Figura 1). No experimento 1 , as reduções foram de $40 \%$ e $72,83 \%$ sobre o número de galhas e ovos do nematoide, respectivamente. No experimento 2, a redução no número de ovos de $\boldsymbol{M}$. javanica apenas foi observada quando o fungo foi incorporado no solo em doses a partir de $5 \mathrm{~g} \mathrm{~kg}^{-1}$ de solo (Figura 1), segundo modelo $\mathrm{Y}=22125-1362,4 \cdot \mathrm{X}+26,036 \cdot \mathrm{X}^{2} \quad\left(\mathrm{r}^{2}=0,73\right)$. Em comparação com o tratamento testemunha com nematoide, as reduções do número de ovos variaram entre $14,20 \%$ a $79,64 \%$, quando foram incorporados ao solo doses entre 5 a $30 \mathrm{~g}$ de substrato colonizado por kg de solo, respectivamente.

Por outro lado, não foi possível ajustar um modelo de regressão para analisar o efeito das doses do fungo na redução de galhas do nematoide nas raízes de tomateiros. Assim, o efeito de cada dose foi individualmente comparado com a testemunha infestada. Em parcelas tratadas com 15, 20 ou $30 \mathrm{~g} \mathrm{~kg}^{-1}$ de solo de substrato colonizado por $\boldsymbol{P}$. chlamydosporia, as reduções nos números de galhas foram de aproximadamente $40 \%$ em relação ao tratamento testemunha (Tabela 2). Os resultados deste trabalho confirmam o potencial antagônico do isolado Pc-10 de $\boldsymbol{P}$. chlamydosporia no controle de M. javanica, assim como foi previamente reportado em outro estudo (DALLEMOLE-GIARETTA et al., 2012). Todavia, a principal diferença entre o presente trabalho e os experimentos anteriores é que não foram utilizados 5.000 clamidósporos/g de solo como fonte de inóculo e sim substrato contendo apenas micélio e conídios do fungo. Os clamidósporos são usualmente utilizados como fonte de inóculo do fungo por serem estruturas que garantem maior sobrevivência do fungo no solo e aumentam a vida- 
Tabela 1 - Efeito da aplicação ao solo de substrato de arroz colonizado por Pochonia chlamydosporia var. chlamydosporia isolado Pc-10 sem presença de clamidósporos sobre número de galhas e ovos de Meloidogyne javanica em raízes de tomateiros e sobre o desenvolvimento da planta em casa de vegetação - Experimento 1.

\begin{tabular}{|c|c|c|c|c|c|}
\hline Tratamentos & Altura $(\mathrm{cm})$ & Massa da parte aérea (g) & Massa de raízes (g) & № de galhas* & № de ovos* \\
\hline Testemunha (sem nematoide) & $70,6^{\mathrm{ns}}$ & $52,6^{\mathrm{ns}}$ & $11,9^{\mathrm{ns}}$ & - & - \\
\hline Testemunha (com nematoide) & 68,4 & 49,8 & 10,9 & $530 \mathrm{a}$ & 89.039 a \\
\hline Pochonia chlamydosporia & 70,0 & 55,2 & 12,2 & $318 \mathrm{~b}$ & 24.184 b \\
\hline
\end{tabular}

Médias de oito repetições. ${ }^{\text {ns }}$ Não significativo pelo teste F, a 5\% de probabilidade. *Médias seguidas pela mesma letra na coluna não diferem entre si pelo teste $\mathrm{F}$ a $5 \%$ de probabilidade. Os dados dos números de ovos foram transformados em Log ${ }_{10}(\mathrm{X})$ para análise estatística. Valores originais são apresentados na tabela.

de-prateleira dos produtos formulados a partir do antagonista (KERRY \& BOURNE, 2002; FERRAZ et al., 2010). No entanto, observou-se que, mesmo sem a presença de clamidósporo no substrato, o fungo foi capaz de controlar $\boldsymbol{M}$. javanica (Tabelas 1 e 2, Figura 1) e sobreviver no solo (Tabela 2). Os valores de unidades formadoras de colônias (UFCs) do fungo nas amostras de solo coletadas em parcelas dos diferentes tratamentos aos 45 dias após o início do experimento variaram de $4,5 \times 10^{3}$ a $4,0 \times 10^{4}$ por grama de solo (Tabela 2). Estes valores de UFCs de $\boldsymbol{P}$. chlamydosporia são semelhantes àqueles obtidos em outros estudos, quando foi aplicado apenas clamidósporos do fungo no solo e houve controle do nematoide das galhas (HIDALGODÍAZ et al., 2000; DALLEMOLE-GIARETTA et al., 2011; DALLEMOLE-GIARETTA et al., 2012). No presente estudo, os grãos de arroz atuaram como fonte de matéria orgânica e garantiram a energia necessária para o estabelecimento e crescimento do fungo no solo (LOPES et al., 2007).
No processo de produção de bionematicida a base de $\boldsymbol{P}$. chlamydosporia, apenas os clamidósporos são extraídos do substrato de cultivo do fungo. Consequentemente, os grãos de arroz contendo apenas micélio, conídios e, possivelmente, uma pequena quantidade de clamidósporos do fungo, contidos internamente no substrato, são comumente considerados como subprodutos do processo. Portanto, considerando os resultados do presente trabalho, tal subproduto não deve ser descartado, pois contém propágulos do fungo e fonte adicional de energia que garantem o controle de M. javanica e o estabelecimento do antagonista no solo.

\section{CONCLUSÃO}

A incorporação ao solo de grãos de arroz colonizados por $\boldsymbol{P}$. chlamydosporia contendo apenas micélio e conídios do fungo foi eficiente no controle de $\boldsymbol{M}$. javanica, principalmente em doses superiores a $5 \mathrm{gg}^{-1}$ de solo.

Tabela 2 - Efeito da aplicação ao solo de diferentes quantidades de grãos de arroz colonizados por Pochonia chlamydosporia var. chlamydosporia isolado Pc-10 sem presença de clamidósporos sobre o desenvolvimento de tomateiro, o número de galhas de Meloidogyne javanica nas raízes e a população do fungo no solo. Experimento 2.

\begin{tabular}{|c|c|c|c|c|c|}
\hline $\begin{array}{l}\text { Doses de grãos de arroz } \\
\text { colonizados }\left(\mathrm{g} \mathrm{kg}^{-1} \text { de solo) }\right.\end{array}$ & Altura (cm) & Massa da parte aérea (g) & Massa de raízes (g) & № de galhas & 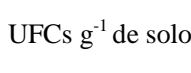 \\
\hline 0 (sem nematoide) & $66,3^{\text {ns }}$ & 37,5 & $10,0^{\mathrm{ns}}$ & - & - \\
\hline 0 (com nematoide) & 59,0 & 35,2 & 8,8 & 615 & - \\
\hline 1 & 65,8 & 37,3 & 8,8 & 642 & $4,5 \times 10^{3+}$ \\
\hline 5 & 62,8 & $41,2^{*}$ & 10,9 & 593 & $2,4 \times 10^{4}$ \\
\hline 10 & 71,8 & $42,3^{*}$ & 10,9 & 428 & $3,5 \times 10^{4}$ \\
\hline 15 & 63,9 & $42,2 *$ & 9,5 & $351^{*}$ & $4,0 \times 10^{4}$ \\
\hline 20 & 68,3 & $44,7 *$ & 9,4 & 418 & $1,8 \times 10^{4}$ \\
\hline 25 & 64,1 & $44,5^{*}$ & 11,5 & $359 *$ & $2,4 \times 10^{4}$ \\
\hline 30 & 61,7 & $46,9 *$ & 10,7 & $378^{*}$ & $1,4 \times 10^{4}$ \\
\hline
\end{tabular}

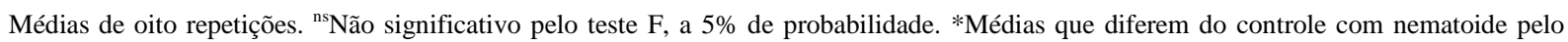
teste de Dunnett, a 5\% de probabilidade. ${ }^{+}$População de Pochonia chlamydosporia Pc-10 no solo infestado com Meloidogyne javanica aos 45 dias após o transplantio das plântulas de tomateiro. 


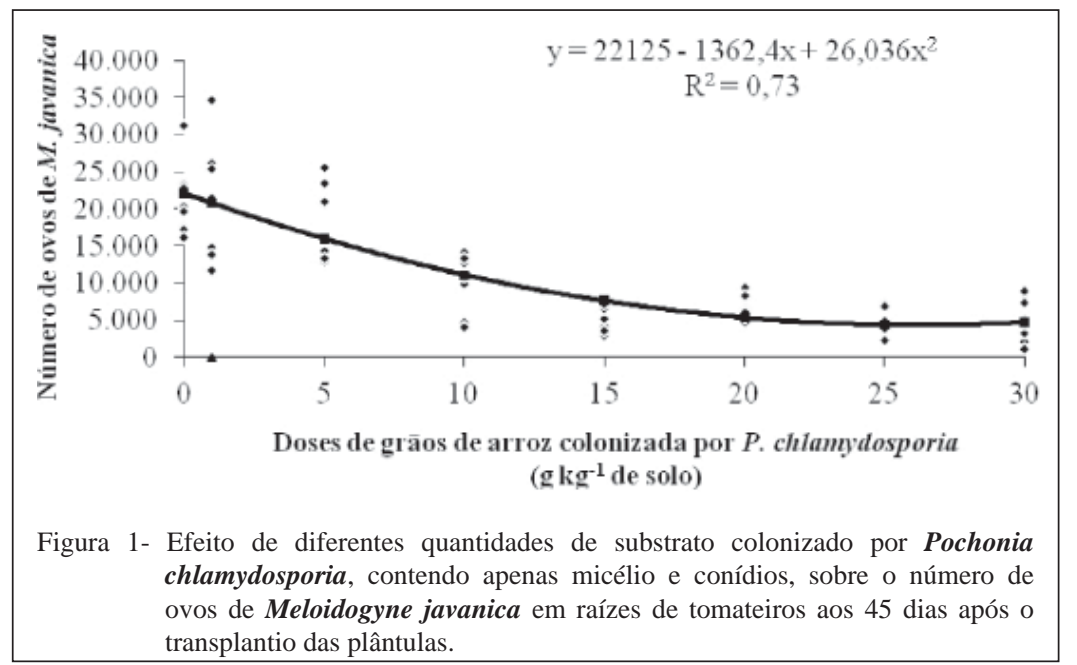

\section{REFERÊNCIAS}

BONETI, J.I.S.; FERRAZ, S. Modificação do método de Hussey e Barker para a extração de ovos de Meloidogyne exigua de cafeeiro. Fitopatologia Brasileira, Brasília, v.6, p.553, 1981 (Resumo).

DALlemole-GiARETTA, R. et al. Cover crops and Pochonia chlamydosporia for the control of Meloidogyne javanica. Nematology, Leiden, v.13, n.8, p.919-926, 2011. Disponível em: $<$ http://dx.doi.org/10.1163/138855411X563875>. Acesso em: 23jan. 2013

DALlEMOLE-GIARETTA, R. et al. Screening of Pochonia chlamydosporia Brazilian isolates as biocontrol agents of Meloidogyne javanica. Crop Protection, Amsterdam, v.42, p.102-107, 2012. Disponível em: <http://dx.doi.org/10.1016/j. cropro.2012.06.002>. Acesso em: 23 jan. 2013.

FERRAZ, S. et al. Manejo sustentável de fitonematoides. Viçosa: UFV, 2010. 306p.

FREITAS, L.G. et al. Controle de Meloidogyne javanica em tomateiro pela produção de mudas e substrato infestado com Paecilomyces lilacinus. Nematologia Brasileira, Piracicaba, v.1, n.23, p.65-73, 1999. Disponível em: <http://docentes.esalq.usp.br/sbn/nbonline/ ol\%20231/65-73\%20pb.pdf>. Acesso em: 13 jun. 2013.

FREITAS, L.G. et al. Controle Biológico de Nematóides: estudo de casos. In: ZAMBOLIM, L.; PICANÇO, M.C. (Org.). Controle biológico de pragas e doenças - exemplos práticos. Visconde do Rio Branco, MG: Suprema, 2009. p.41-82.

GASPARD, J.T. et al. Association of Verticillium chlamydosporium and Paecilomyces lilacinus with root-knot nematode infested soil. Journal of Nematology, Hanover, v.22, n.2, p.207-213, 1990. Disponível em: <http://www.ncbi.nlm.nih.gov/pmc/articles/ PMC2619028/pdf/207.pdf>. Acesso em: 23 jan. 2013.

HIDALGO-DÍAZ, L. et al. Nematophagous Verticillium spp. in soils infested with Meloidogyne spp. in Cuba: isolation and screening. International Journal of Pest Management, Cardiff, v.46, n.4, p.277-284, 2000. Disponível em: <http://dx.doi. org/10.1080/09670870050206046>. Acesso em: 23 jan. 2013.
HUSSEY, R.S.; BARKER, K.R. A comparison of methods of collecting inocula of Meloidogyne spp. including a new technique. Plant Disease Reporter, Saint Paul, v.57, n.12, p.1025-1028, 1973.

KERRY, B.R.; BOURNE, J.M. A manual for research on Verticillium chlamydosporium, a potential biological control agent for root-knot nematodes. Ghent: IOBC/WPRS, 2002.84p.

LOPES, E.A. et al. Potencial de isolados de fungos nematófagos no controle de Meloidogyne javanica. Nematologia Brasileira, Piracicaba, v.31, n.2, p.20-26, 2007. Disponível em: <http:// docentes.esalq.usp.br/sbn/nbonline/ol\%20312/78-84\%20pb.pdf > . Acesso em: 23 jan. 2013.

MACIÁ-VICENTE, J.G. et al. Colonisation of barley roots by endophytic Fusarium equiseti and Pochonia chlamydosporia: effects on plant growth and disease. Annals of Applied Biology, Warwickshire, v.155, n.3, p.391-401, 2009. Disponível em: <http:// dx.doi.org/10.1111/j.1744-7348.2009.00352.x>. Acesso em: 23 jan. 2013.

MAUCHLINE, T.H. et al. Quantification in soil and the rhizosphere of the nematophagous fungus Verticillium chlamydosporium by competitive PCR and comparison with selective planting. Applied and Environmental Microbiology, Washington, v.68, n.4, p.1846-1853, 2002. Disponível em: <http://dx.doi.org/10.1128/ AEM.68.4.1846-1853.2002>. Acesso em: 23 jan. 2013.

MONFORT, E. et al. Colonization of seminal roots of wheat and barley by egg-parasitic nematophagous fungi and their effects on Gaeumannomyces graminis var. tritici and development of root-rot. Soil Biology \& Biochemistry, Amsterdam, v.37, p.1229-1235, 2005. Disponível em: <http://dx.doi.org/10.1016/j. soilbio.2004.11.019>. Acesso em: 23 jan. 2013.

PÉREZ-RODRÍGUEZ, I. et al. Isolates of Pochonia chlamydosporia var. chlamydosporia from Mexico as potential biological control agentes of Nacobbus aberrans. Nematropica, DeLeon Springs, v.37, n.1, p.127-134, 2007. Disponível em: <http://journals.fcla.edu/nematropica/article/ view/64422/62090>. Acesso em: 23 jan. 2013.

WANG, K. et al. Isolation, selection, and efficacy of Pochonia chlamydosporia for control of Rotylenchulus reniformis on cotton. Phytopathology, St. Paul, v.95, n.8, p.890-893, 2005. Disponível em: <http://dx.doi.org/10.1094/PHYTO-95-0890>. Acesso em: 23 jan. 2013. 